\title{
Lectura crítica del relato audiovisual como fuente de información en el filme Taxi Driver
}

\author{
José Luis Valhondo-Crego* \\ Agustín Vivas Moreno*
}

Artículo recibido:

28 de agosto de 2020

Artículo aceptado:

16 de noviembre de 2020

Artículo de investigación

\section{Resumen}

La presente investigación aborda, desde la metodología de la lectura crítica, el filme de ficción como documento audiovisual. Parte de la hipótesis de cómo el relato audiovisual es capaz de representar, mediante su lectura reflexiva, el espíritu de una época. Ciertos fenómenos sociales, como la soledad, pueden entenderse de un modo más profundo a partir de la mirada subjetiva de un autor y su obra ficticia. Desde décadas recientes, vivir solo ha dejado de ser algo estadísticamente marginal o socialmente extraño. Por una parte, se ha convertido en una oportunidad vital para alcanzar objetivos personales; por la otra, en un problema

* Grupo ARDOPA. Facultad CC. Documentación y Comunicación, Universidad de Extremadura, España

jlvalcre@unex.es aguvivas@unex.es

INVESTIGACIÓN BIBLIOTECOLÓGICA, vol. 35, núm. 87, abril/junio, 2021, México, ISSN: 2448-8321 pp. 171-186 
social que implica a un número cada vez mayor de individuos. A través de un ensayo de lectura del relato audiovisual, este artículo examina cómo se hace sensible al espectador la soledad a través del caso de estudio del filme Taxi Driver, con guion de Paul Schrader y dirección de Martin Scorsese. Se examina el modo en que se encarna esa soledad a través de la puesta en escena de un guion en el que la escritura de un diario personal es clave para racionalizar las imágenes documentales de una época.

Palabras clave: Documento Audiovisual; Fuente Informativa; Lectura Crítica; Relato Audiovisual; Soledad; Taxi Driver

Critical reading of the audiovisual narrative as a source of information in TaxiDriver

José Luis Valhondo-Crego and Agustín Vivas Moreno

\section{Abstract}

From a critical reading methodology, this article focus on the fiction film as an audio-visual document. The starting hypothesis considers how the audio-visual narrative is able to represent, through its reflective reading, the spirit of an era. Some social phenomena such as loneliness can be understood in a deeper way from the subjective gaze of an author and his fictional work. Since recent decades, living alone has ceased to be statistically marginally or socially bizarre. On the one hand, it has become a vital opportunity to achieve personal goals; on the other, it has come to be a social problem involving an increasing number of individuals. Through a reading essay on the audio-visual narrative, this article examines how loneliness is made sensitive to viewers through the case study of the film Taxi Driver, with the script of Paul Schrader and the direction of Martin Scorsese. The film examines how this loneliness is embodied through the staging of a script in which writing a personal diary is key to rationalizing the documentary images of an historical period.

Keywords: Audiovisual Document; Informative Source; Critical Reading; Audiovisual Story; Solitude; Taxi Driver 


\section{INTRODUCCIÓN}

— ste texto propone analizar, a través de una lectura crítica, el modo esté¿tico en que se genera la producción-interpretación de las imágenes en un filme como Taxi Driver. En esencia, tratar el cine y, fundamentalmente, el relato audiovisual, como instrumento susceptible de una lectura crítica. Esa lectura permite reconstruir una representación existencial del protagonista que se enfrenta a la soledad, la falta de identidad, la incomunicación, la anomia o la alienación en el contexto de la posmodernidad. Dicho de otra forma, se considera el discurso de las imágenes como un discurso de signos que, al igual que las palabras, funciona como un binomio inextricable de significante y significado. A través de la metodología de la lectura crítica se torna posible analizar esos signos en su contexto discursivo para desarrollar y contribuir a la reflexión sobre el individuo y su sociedad. Se trata de una metodología que pone en juego la interdisciplinariedad de la bibliotecología.

La lectura crítica se comporta como elemento constitutivo de la formación de las personas, contribuyendo al debate, el antidogmatismo, la democracia y el progreso científico. Esto es, la lectura crítica como antídoto del pensamiento único.

\section{AlCANCE y METODOLOGÍA EMPLEADA}

Como ya ha quedado indicado, seguimos la metodología del "modelo de lectura crítica". Se trata de un método que han desarrollado autores como Van Dijk (1993) o Cassany (2003). Al decir del profesor López Yepes (2019: 33), la lectura crítica tiene como objetivos:

- Fomentar la reflexión y el espíritu crítico;

- Aprender e idear nuevos conocimientos científicos.

La metodología de la lectura crítica interactúa con el relato audiovisual explicitado para, en consecuencia, abrir nuevas vías de reflexión y debatir sobre el contenido que nos ofrece el documento audiovisual (Encabo Fernández, 2013: 371; Vivas Moreno y Martos García, 2010). Esa interacción se acomete definiendo incialmente el fragmento a examinar y las unidades de análisis. A continuación cada unidad se conceptualiza en relación a una codificación (Anexo). Los resultados del análisis se contextualizan en relación al filme completo y al proceso de producción.

Así pues, siguiendo este modelo, establecemos los siguientes objetivos en etapas: 
- Contextualizar la producción del filme. Antes de adentrarnos en el tema que nos concierne, el análisis de la soledad como elemento de aplicación del "modelo de lectura crítica" y su ejemplificación en el relato audiovisual, es preciso contextualizarlo, siquiera brevemente, para la comprensión del tema de análisis.

- Seleccionar el fragmento que consideramos clave para el estudio. En concreto, ese fragmento de 10 minutos abarca desde el comienzo hasta el momento en que Travis descubre a Betsy. La justificación de esta elección se relaciona con el giro narrativo del filme. Ese fragmento contiene el planteamiento de la trama y la presentación del personaje protagonista. Naturalmente, el método de lectura crítica resuelve el empleo del resto del filme como contexto narrativo.

- Indicar las unidades de análisis. En el caso del guion, esas unidades son las intervenciones de los personajes y las acotaciones; en el caso del filme, los planos y las escenas constituirán las unidades a examinar.

- Comparar los resultados del análisis del guion y del filme en el fragmento seleccionado, extrayendo conclusiones acerca de la estética respecto a la soledad postmoderna.

- Examinar el proceso creativo entre el guionista (Paul Schrader) y el director (Martin Scorsese). Intentaremos observar la afinidad estética entre Schrader y Scorsese. En este sentido, reconoceremos cómo Scorsese también creció en una subcultura muy religiosa, la de la comunidad italoamericana de posguerra en Nueva York. Pensó de joven en ordenarse sacerdote para terminar abrazando el cine como profesión, con una fe casi religiosa en las imágenes.

\section{LECTURA CONTEXTUAL: PARADOJAS DEL INDIVIDUALISMO EN LA POSMODERNIDAD}

Taxi Driver se produce en 1976 con dirección de Martin Scorsese y guion de Paul Schrader. Bernard Hermann confecciona la música de la película y Michael Chapman se ocupa de la dirección fotográfica. El elenco incluye en los papeles principales a Robert De Niro, Cybill Shepherd, Jodie Foster y Harvey Keitel. Con un metraje de 114 minutos, el filme se divide en dos actos separados por la decisión del protagonista de cometer un crimen, aproximadamente en el minuto 51. En los 10 primeros minutos se construye la atmósfera del relato y se perfila al protagonista. En ese intervalo, el personaje principal descubre a Betsy. El deseo de conocerla se convierte en el objetivo que impulsará sus acciones. 
Este filme se produce tras el impacto cultural de Mayo del 68, la crisis del petróleo de 1973 y el final de la guerra de Vietnam (1975). A nivel sociológico, se asiste a la crisis del modelo de Bienestar Social basado en una cultura cohesionada en lo económico, político y social. Hasta la segunda mitad del siglo XX, vivir solo era una excentricidad, de manera que la sociedad se había organizado en torno al núcleo familiar. Como señala Klinenberg (2013), nunca en la historia humana existieron tantos individuos viviendo por su cuenta, solos, sin compartir techo con una familia o una comunidad. Los datos nunca hablan por sí mismos, pero sí resultan imprescindibles para interpretar la realidad. En 1950, 22 \% de los estadounidenses eran solteros. Cuatro millones vivían solos, lo que constituía $9 \%$ de todos los hogares. Hoy en día, $50 \%$ son solteros, y 31 millones (uno de cada siete) viven solos, lo que supone $28 \%$ de los hogares. Y no son los Estados Unidos quienes encabezan este ranking mundial sino los países europeos escandinavos.

La soledad se representa socialmente como oportunidad o amenaza. Klinenberg (2013) refiere dos tradiciones americanas sobre el beneficio de esta forma de ejercer el individualismo, la utilitarista y la expresiva:

- El individualismo utilitarista se ejemplifica en Benjamin Franklin, quien señalaba que la sociedad progresa cuando deja que sus individuos busquen por su cuenta, de modo racional, sus objetivos vitales.

- El individualismo expresivo es representado por Walt Whitman o Henry David Thoreau. Ambos abogaban por cultivar y celebrar la búsqueda y significado del propio yo a través de la soledad de la Naturaleza o la Poesía.

Por el contrario, encontramos multitud de ensayos y estudios sociológicos que representan la soledad como amenaza. La causa del malestar social procede de la destrucción de las comunidades y el individualismo exacerbado. Desde El declive del hombre público, de Sennett (2002), hasta La muchedumbre solitaria de Riesman (1981), o el influyente libro de Putnam (1995), Bowling alone, se advierte que la racionalización de la vida cotidiana ha contribuido a destruir lo que llamamos Sociedad, la misma que Margaret Tatcher consideraba inexistente. En el panorama europeo, pensadores como Habermas (2010) han basado su obra en explorar la necesidad de una esfera pública poderosa para prevenir nuevos fascismos y evitar reproducir los gérmenes sociales del nazismo.

Una vez realizada esta contextualización del filme, se muestra a continuación el resultado del análisis realizado. 
Los primeros fotogramas de Taxi Driver muestran un taxi surgiendo lentamente, desde un ángulo bajo y oblicuo, de la niebla de Nueva York, con los acordes de la música de Bernard Hermann. Para el guionista esa imagen condensaba los significados del tema que quería tratar y la describió como un "taxista enclaustrado en un ataúd de hierro surcando la ciudad" (Wade, 2017). Cuando tuvo esa inspiración visual, Schrader convalecía en un hospital, ingresado por una úlcera de estómago. Se había separado de su pareja, vivía en un coche, bebía en exceso y frecuentaba cines porno cuando sufría insomnio. La metáfora de su alter ego taxista apuntaba a un arquetipo moderno, un voyeur que lucha por racionalizar la furia de las imágenes que se cuelan cada noche en su retina, en su incesante merodeo por la ciudad de Nueva York.

Scorsese tradujo visualmente la metáfora de Schrader (2018) cuando éste imaginó el germen de su guion como un ataúd de hierro surcando la ciudad (Figura 1).

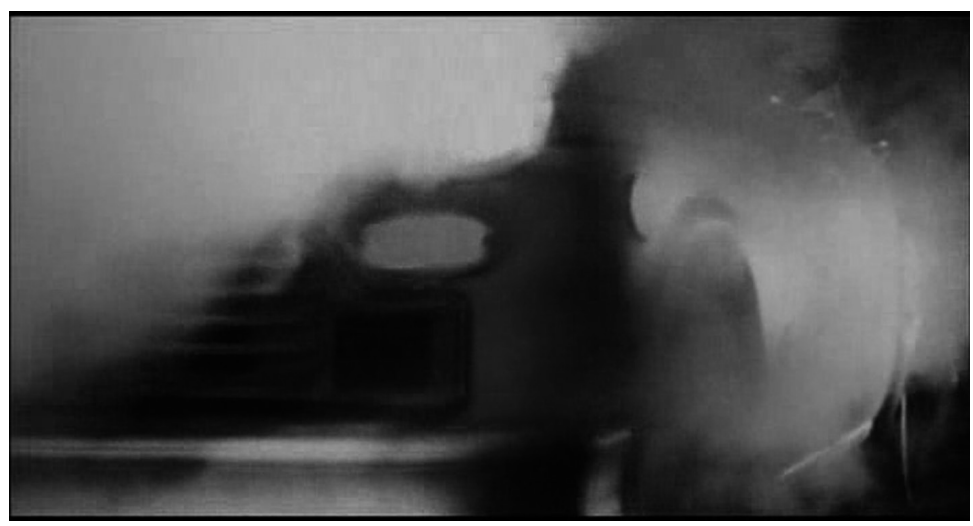

Figura 1. Fotograma del taxi

El guion clásico no suele abrir con una cita, pero Schrader lo hace citando una frase del escritor Thomas Wolfe: "La mayor convicción de mi vida reside ahora en la creencia de que la soledad, lejos de ser un raro y curioso fenómeno, es el hecho fundamental e inevitable de la existencia humana" (God's Lonely Man, 1941). Emplear esa cita forma parte del pastiche posmoderno de la película y funciona a modo de tono o clave de la melodía de lo que vendrá después en el resto de la pieza. Esa clave gira en torno a la conciencia humana de la soledad tal y como el propio Schrader reconoce (Brady, 2013); una soledad que el personaje rumia a lo largo de toda la película. 


\section{Primer ejemplo de lectura critica: rasgos objetivos y estados mentales}

Tras esa cita inicial el guion destaca la descripción del protagonista: "Travis es joven, delgado, curtido. Viste tejanos y botas de vaquero, una camisa de cuadros y una raída cazadora del ejército con un lema donde se puede leer 'King Kong Company 1968-1970'”.

Frente a esas descripciones objetivas localizamos en esa acotación la descripción de estados mentales que sólo pueden ser leídos a través de la observación de la conducta externa. Por ejemplo, cuando el guion señala lo siguiente (https://www.dailyscript.com/scripts/taxidriver.html, cursivas nuestras): "Detrás de esa sonrisa, tras sus oscuros ojos, en sus mejillas demacradas, podemos ver las manchas ominosas causadas por una vida de miedo íntimo, de vacío, de soledad". El director traduce esa descripción en una serie de planos de la mirada de Travis a su espejo retrovisor (Figura 2).

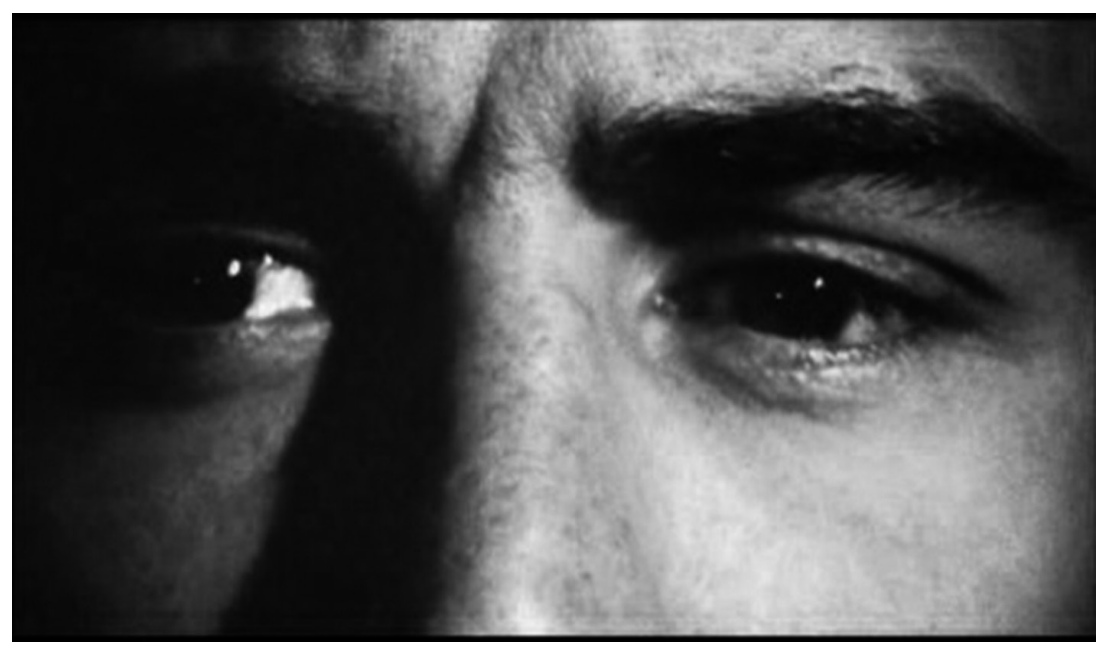

Figura 2. "Detrás de esa sonrisa..."

Schrader despliega también en esa descripción inicial un registro aún más subjetivo respecto a su personaje, relacionado con una imagen ambigua. Lo hace cuando apunta que "parece haber deambulado por un mundo frío, un lugar donde la gente apenas se comunica". Se trata de una descripción posibilista y metafórica, en la que el autor propone un boceto difuso, nada clásico, del personaje; como si hubiera algo en él que se escapa al autor y que quiere compartir con el espectador. 


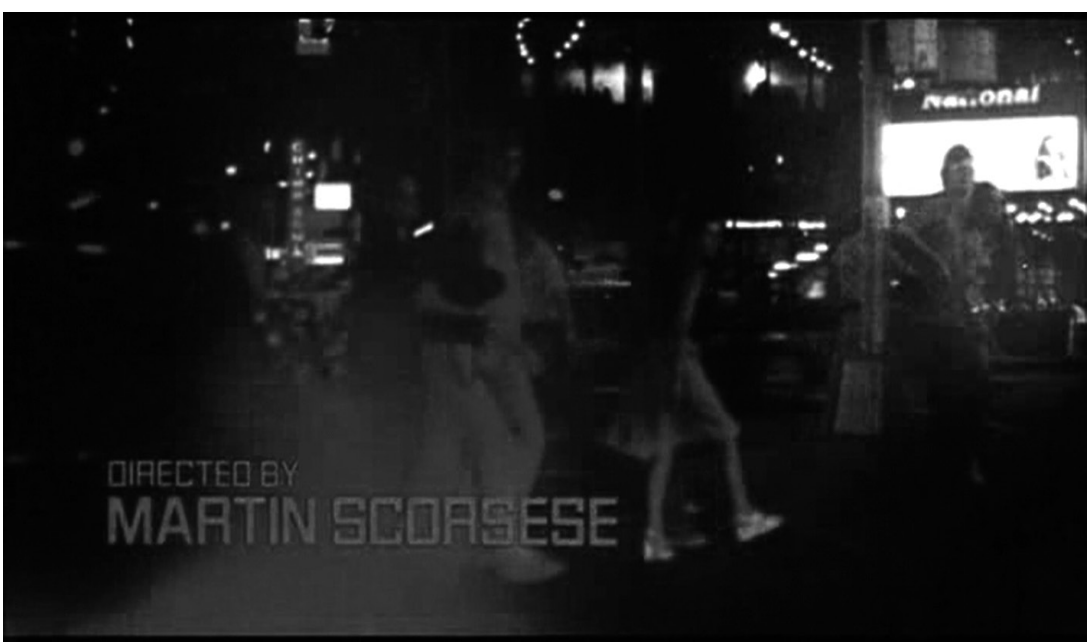

Figura 3. "Una oscura sombra..."

\section{Segundo ejemplo de lectura crítica: el individuo frente a la masa}

Otro elemento en esa descripción inicial del personaje lo relaciona con el resto de la sociedad. "Travis va a la deriva en la vida nocturna de Nueva York, como una oscura sombra entre otras sombras aún más oscuras. Pasando desapercibido, sin motivos para que nadie se fije en él. Travis parece camuflarse entre lo que le rodea".

En la traducción visual, Scorsese opta por unas imágenes distorsionadas de gente anónima, con filtros de colores primarios (rojo y azul) que dejan estelas. Figuras fantasmagóricas u oníricas se pasean delante de la mirada del taxista (Figura 3). Se trata de la masa indistinguible que funciona como otro personaje del relato.

Las imágenes de los créditos proponen unas coordenadas estéticas y temáticas condensadas y traducidas en tres símbolos básicos que se encadenan en la secuencia: Taxi, Mirada de Travis, Muchedumbre. Hablamos de una sintaxis visual que se replica a lo largo del guion para incidir en la subjetividad del relato a través de los ojos de Travis, además de señalar la separación entre el taxista y la realidad indescifrable que cada noche observa. ¿Quién está mirando ese espectáculo? La siguiente escena responde: se trata de Travis Bickle, alguien con insomnio que acude a una empresa de taxis para hacer algo de provecho por las noches. 


\section{Tercer ejemplo de lectura crítica: un diario para racionalizar las imágenes}

Para clausurar el significado abierto de las imágenes, el guionista recurre a un diario escrito que confecciona el protagonista. Scorsese toma del guion el primer monólogo en Voice Over (V.O. en adelante) y lo edita con imágenes de una panorámica del interior de la vivienda con Travis escribiendo en su diario. El guion describe lo siguiente: "La CÁMARA realiza una panorámica, examinando el apartamento de Travis. Como poco, resulta extraño [...]. No hay mobiliario, un colchón raído se apoya contra la pared, fotos pornográficas, una televisión portátil, una bandera, unos cables rotos en la pared donde en otro tiempo hubo un teléfono".

La continuidad se asegura gracias a esa voz interna de Travis cuya significación estética principal en el filme consiste en intentar fundir relato e identidad del personaje. En el fondo, ese diario se parece a lo que Barthes (2007) señalaba respecto al anclaje que ejercen los pies de foto en las imágenes que comentan.

El flujo de conciencia no es un recurso clásico en la construcción del personaje fílmico. Se trata de una estrategia del guionista que comunica a su personaje mientras éste se cuenta el relato de su identidad. Estéticamente, también comunica algo muy importante: Travis está solo. No escribe un diario por placer expresivo, lo hacer como ejercicio de control (Figura 4).

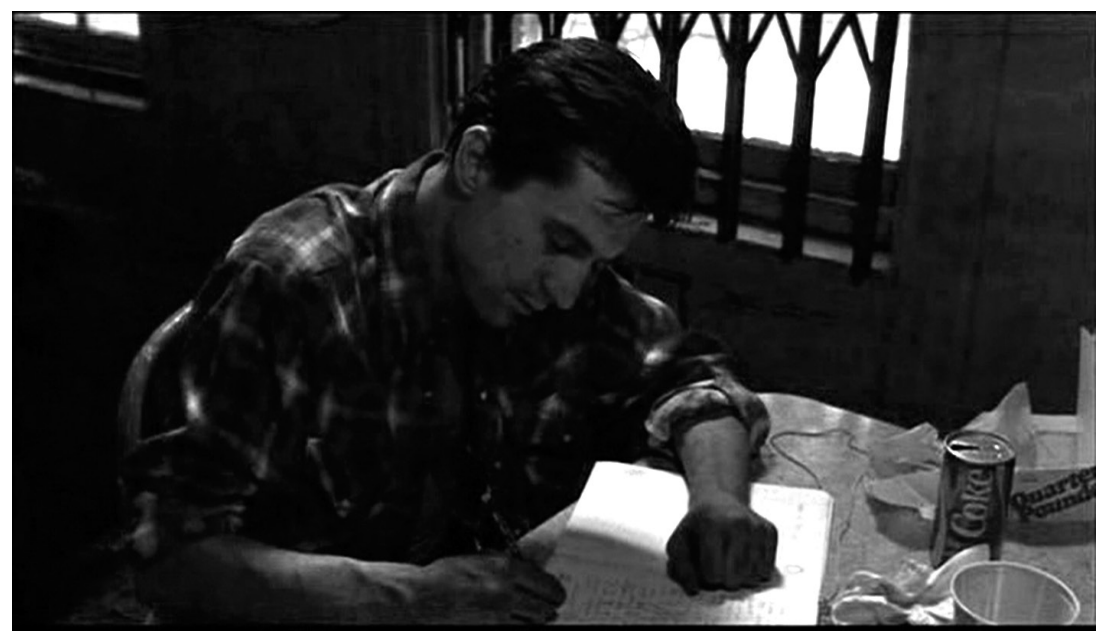

Figura 4. Travis escribe un diario 
El recurso al V.O. permite al personaje la posibilidad de construirse a través del diario, como un sujeto racional que es capaz de "contarse a sí mismo". Foucault (1990) lo consigna entre esas herramientas o tecnologías del yo con las que el sujeto moderno intenta someterse a su propia disciplina. Lo más interesante del V.O. es su doble fin como tecnología del yo, tanto para el guionista como para su personaje. El primero recurre a esta técnica para orientar el curso del relato, del mismo modo que el personaje la emplea para ordenar su existencia. Travis está obsesionado con la organización de sus cosas domésticas, lo que viene a reflejar también su necesidad de orden social.

Estas intervenciones de Travis en su diario jalonan el arco de transformación del personaje que inventa objetivos con el fin de estructurar su caótica existencia. A diferencia de un relato tradicional, y con ello de un sujeto clásico, este personaje tiene como objetivo encontrar un objetivo (Dancyger y Rush, 2013). El recurso del diario sirve a Schrader para hacer sensible la naturaleza de su personaje y renovar el V.O. del filme noir clásico, con un sentido aún más existencialista.

El punto medio de la película o punto de crisis está dominado por una intervención en el diario, con función expresiva y estructural: "La soledad me ha perseguido durante toda mi vida, por todas partes: en los bares, en los coches, en las aceras, en las tiendas, por todas partes, no tengo escapatoria, soy un hombre solitario". Expresiva porque figura como elemento clave para comprender el estado emocional del personaje. Desde la perspectiva aristotélica se trata de la anagnórisis o toma de conciencia del protagonista. Estructural porque coincide con el punto crítico en el cual Travis decide pasar a la acción. La intervención parafrasea la cita de Thomas Wolfe con la que Schrader enmarca su guion y suena como elemento central de la existencia de Travis, como una falta original o una fatalidad del destino.

Toda la primera parte del filme exhibe un esfuerzo denodado por parte del protagonista por ordenar su mundo, en especial su percepción. Schrader construye a Travis Bickle señalando cómo percibe la realidad y qué significado confiere a lo que ve. El personaje destaca una figura sobre un fondo de su mundo circundante, al tiempo que produce una interpretación sobre él.

Hemos apuntado que la multitud anónima de Nueva York es un personaje indispensable en esta historia. Travis se siente solo frente a esa masa. Su personaje se encarna frente a esa muchedumbre solitaria a la que teme (Figura 5). Si al inicio del filme se muestra ya esa imagen (Figura 3), con la incorporación del V.O. se añade la interpretación que Travis le confiere: "Por la noche salen bichos de todas clases: furcias, macarras, maleantes, maricas, lesbianas, drogadictos, traficantes de drogas". Repetirá el mismo pensamiento más tarde y el guionista mostrará el mundo a través de los ojos de Travis para que podamos representárnoslo 
como él lo ve: "Nuestros ojos radiografían las hileras de peatones -desahuciados, yonkis, turistas, putas, homosexuales, hippies. Todos ellos se confunden en las aceras frente a los escaparates iluminados y no significan nada”. Se trata de una masa informe, sin cara, deshumanizada y anónima frente a la que Travis experimenta miedo y asco.

Schrader sigue la técnica de comunicar al personaje desde dentro hacia afuera, tal como prescribiría Stanislavski (1975), tanto con su flujo de pensamiento como con su percepción.

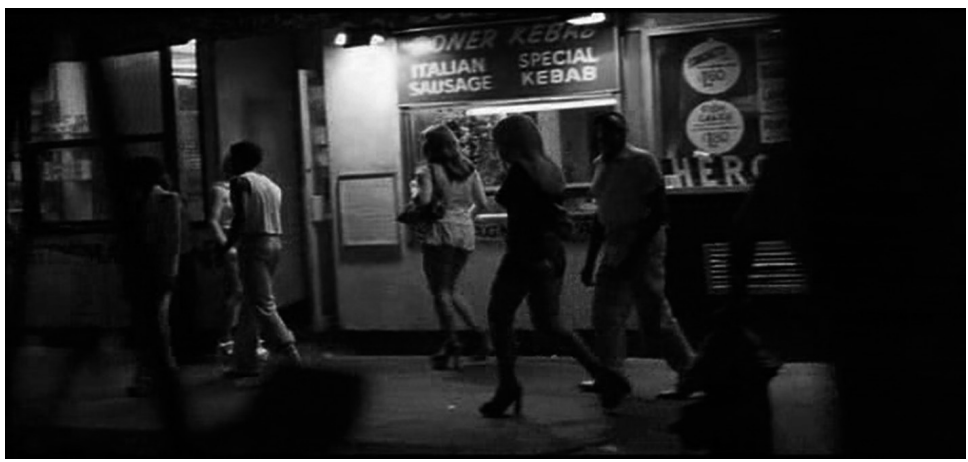

Figura 5. "Por la noche salen bichos de todas clases..."

\section{Cuarto ejemplo de lectura crítica: la pornografía como refugio de las multitudes}

Tras terminar su turno, Travis entra en un cine porno. Escuchamos de nuevo el V.O.: "Doce horas de trabajo y sigo sin poder dormir. Los días pasan uno tras otro, parece que no tienen fin”. Travis frecuenta los cines porno. Este hábito del personaje tiene relación con otra dimensión de su aislamiento: su forma de concebir la sexualidad. En la descripción inicial de Travis, Schrader apunta lo siguiente: "Desprende olor a sexo: sexo enfermizo, reprimido, solitario, pero sexo, al fin y al cabo. Una desbocada energía masculina que le empuja no sabemos en qué dirección”. Su mirada ante el flujo pornográfico de las imágenes refleja la misma impotencia que siente respecto a asimilarse a la masa que le rodea. En esa representación de la soledad, la posición del espectador de pornografía en el cine replica la del conductor del taxi. Mira sin actuar, sin poder someter sus prejuicios a examen. Las imágenes sustituyen su experiencia con la realidad y lo mantienen a distancia de ésta. En ambas situaciones, el taxi y la butaca del cine le sirven como refugio frente a las multitudes. 


\section{Quinto ejemplo de lectura crítica: Betsy o cómo la multitud se individualiza}

Frente a la masa informe, el relato hace emerger a Betsy. Aquí Scorsese recrea el guion de Schrader con una puesta en escena diferente. En vez de estar sentada en las oficinas (en el guion), Betsy aparece caminando en cámara lenta mientras entra en esas oficinas. Esta opción estilística de Scorsese aumenta el efecto de fascinación cuando es el propio Scorsese el que sale en el plano en el que vemos por primera vez a Betsy, además de optar por la ralentización de la imagen. Frente a la masa indistinguible de la calle, se erige la figura de Betsy (Figura 6). Justo antes de esa aparición, Scorsese también opta por planos de día para representar a la masa, pero siguiendo la lógica de la distorsión de la mirada de Travis, el director escoge un gran angular con steadycam, produciendo una impresión de extrañeza.

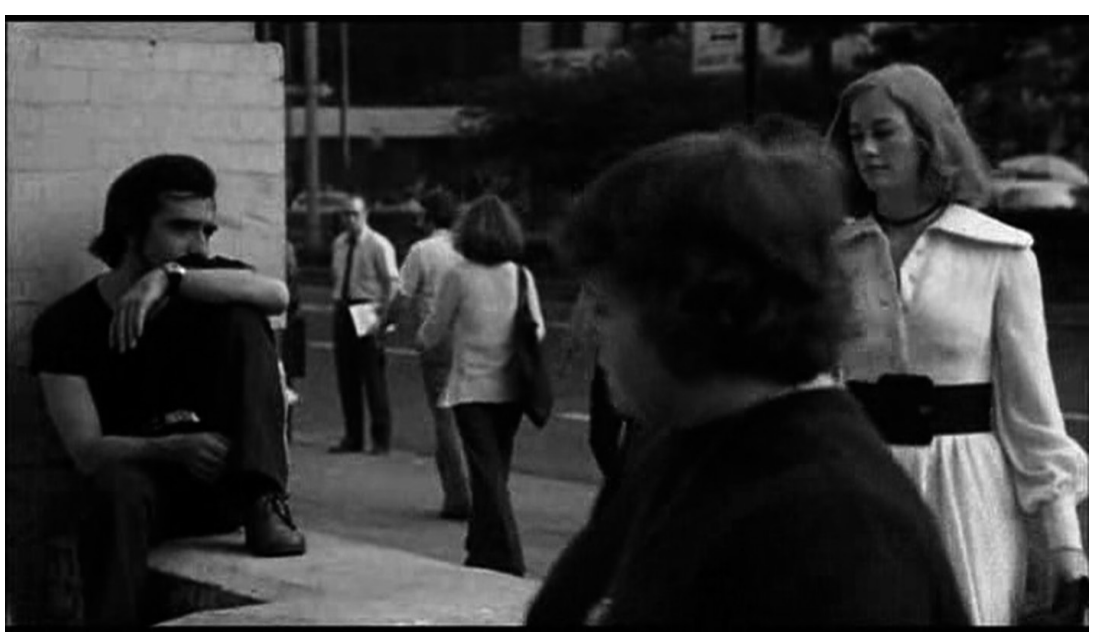

Figura 6. "La vi por primera vez..."

Betsy sirve al guionista para revelar al personaje al modo tradicional, a través de los ojos de otro personaje. En el guion, Travis se dirige hacia la oficina para presentarse a Betsy. Tras hacerlo le confiesa que es la mujer más bella que ha conocido. Antes de mostrar la respuesta de Betsy, Schrader describe su pensamiento:

BETSY por un momento queda atónita, aunque encantada. La presencia de TRAVIS tiene esa carga sexual definitiva. Tiene esas cualidades especiales que BETSY busca. Ella siente que hay algo especial en ese joven que está frente a ella. Además, está esa sonrisa que la desarma. Él es, como diría Betsy, 'fascinante'. 
Por primera vez en el relato, Travis consigue establecer cierta intimidad con otro ser humano, individualizar a esa masa que teme, dar un paso para encarnar la fantasía pornográfica en alguien que le atrae sexualmente. Por eso el espectador puede quedarse atónito cuando en la primera cita, Travis invita a Betsy a un cine porno. En la línea del sujeto postmoderno, las motivaciones de Travis parecen inescrutables.

\section{CONCLusiones}

1. La lectura crítica, aplicada al cine, se constituye como metodología que analiza el documento, fomenta la reflexión y el espíritu crítico e impulsa la formulación de nuevos conocimientos científicos. Mediante su constitución, se interactúa con el relato audiovisual para debatir sobre el contenido que nos ofrece el documento audiovisual.

2. La lectura crítica ha resultado un método apropiado para explorar la estética respecto a la soledad postmoderna en Taxi Driver.

3. Podemos establecer los siguientes elementos que articulan nuestro ensayo de lectura crítica sobre la estética de la soledad en Taxi Driver:

- El relato audiovisual como representación de la soledad postmoderna. Taxi Driver brinda al espectador una representación de la soledad postmoderna a través de su encarnación en un sujeto cuya caracterización fundamental procede de la escritura de un diario con el que pretende, a través de la palabra, domesticar su imagen propia y la de los otros. Como tecnología del yo moderna, el diario no alcanza para crear un relato satisfactorio para el protagonista. A diferencia del relato clásico, en éste no existe en principio un objetivo diáfano que oriente la acción. El protagonista vagabundea, no sólo de modo literal, sino también como metáfora de su búsqueda personal de sentido entre una multitud de imágenes. Dicho de otro modo, el objetivo del personaje se centra en descubrir su objetivo en la vorágine de significados que le rodean.

- El guion como elemento identitario. La escritura del guion de Schrader replica como relato la conformación de la identidad de Travis. El guionista desnuda ese proceso que la Modernidad daba por sentado cuando señalaba que el sujeto es capaz de crear un relato propio coherente y ordenado de sí mismo. El guion proporciona claves clásicas y objetivas sobre la caracterización del personaje: "Travis Bickle, 26 años, delgado, curtido, el típico solitario [...] Viste tejanos y botas de vaquero, una camisa de cuadros y una raída cazadora del ejército". El guion también describe al personaje 
a través de claves subjetivas, autoconscientes y comunicables. Son todos los estados mentales que pueden ser leídos por el espectador a través de la observación de la conducta: "Tiene una mirada firme y tranquila y una sonrisa que desarma, que brilla como por arte de magia, iluminándole todo el rostro". Finalmente, el guion incluye una serie de metáforas ambiguas que no permiten delimitar con precisión los contornos del protagonista: "Parece haber deambulado por un mundo frío, un lugar donde la gente apenas se comunica”. Ese es precisamente el terreno que Travis intenta explorar a través de su diario, al tiempo que Schrader lo hace mediante su relato guionizado. Ahí es donde mejor se puede trasladar el tema de la soledad del individuo.

- La imagen como elemento vertebrador de la identidad. No se trata de una soledad moderna, elegida, que persigue un objetivo expresivo (en la tradición de Thoreau o Whitman) o utilitario (en la línea de Franklin). La soledad del diario de Travis es la del individuo que lidia por construir un relato de significados sólidos, una soledad necesaria para redimirse. En esa construcción juegan un papel fundamental las imágenes que el protagonista pretende domesticar con la palabra. Esas imágenes tienen que ver con él a través de los otros, con cómo el propio Travis se representa a los otros. El taxi lo protege y aísla de la masa que observa en las calles, frente a la que se construye por identificación negativa. Él es todo lo que esa masa no es; aunque, por supuesto, muchas de sus conductas reflejen ese caos del que rechaza formar parte. En vez de someter esas imágenes a un contraste experiencial, Travis se limita a la posición del voyeur desde el asiento del taxi, la butaca del cine porno o la silla frente a la televisión. La soledad es una soledad frente a las imágenes que saturan su mapa de significados sociales.

- El relato elemento de búsqueda del yo. A diferencia del relato clásico, el espectador no consigue leer en el protagonista unas motivaciones del pasado que logren explicar la conducta de Travis. Su perfil tampoco incluye identificación de clase de ningún tipo (económica, social o política). Como mucho, Travis hace gala de unos valores culturales muy conservadores respecto al entorno en el que vive. En definitiva, lo único que Schrader pretende dejar claro acerca de su alter ego es que se trata de un enigma incluso para él mismo, tal y como queda bien fundamentado en los diálogos (del guion) que entabla con Betsy. Travis emprende un ciclo de redención y trascendencia para explorar ese enigma y luchar en la batalla por el sentido de su propio yo. 


\section{REFERENCIAS}

Baker, A., ed. 2015. A Companion to Martin Scorsese. Malden, MA: Wiley Blackwell.

Barthes, R. 1984. "La mort de l'auteur. Dans Le bruissement de la langue”, en Essais critiques IV, 63-69. Paris: Seuil.

Barthes, R. 2007. El imperio de los signos. Barcelona: Seix Barral.

Benjamin, W. 2017. “The Work of Art in the Age of Mechanical Reproduction”, en Aesthetics: A reader in philosophy of the arts, 4a. ed., editado por D. Goldblatt, L. B. Brown y S. Patridge, 66-69. London: Taylor \& Francis. https://doi.org/10.4324/9781315303673

Brady, J. 2013. The Craft of the Screenwriter. Nueva York, EE.UU.: Simon and Schuster.

Cassany, D. 2003. "Aproximaciones a la lectura crítica: teoría, ejemplos y reflexiones”. Tarbiya 32: 113-132.

Dancyger, K. y J. Rush. 2013. Alternative Scriptwriting. Rewriting the Hollywood Formula. Burlington, MA: Taylor \& Francis.

Du Gay, P. y S. Hall. 2001. Questions of cultural identity. London: Sage.

Ekman, P. 1992. “Are There Basic Emotions?” Psychological Review 99 (3): 550-553. https://doi.org/10.1037/0033-295X.99.3.550

Encabo Fernández, E. 2013. "Lectura crítica", en Diccionario de nuevas formas de lectura y escritura, editado por E. Martos Núñez y M. Campos Fernández-Figares, 371-372. Madrid: RIUL Santillana.

Foucault, M. 1990. Teconologías del yo y otros textos afínes. Barcelona: Paidós.

Habermas, J. 2010. Teoría de la acción comunicativa. Madrid: Trotta.

Hall, S. 1996. Modernity: an introduction to modern societies. London: Blackwell.

Harris, M. 2010. Antropología Cultural. Barcelona: Alianza Editorial.

Humphrey, N. 1996. La Mirada interior. Barcelona: Alianza Editorial.

Kolker, R. P. 2011. A cinema of loneliness: Penn, Stone, Kubrick, Scorsese, Spielberg, Altman. New York, Oxford: Oxford University Press.

Konow, D. y J. Mercurio. 2015. Transformation in Art: The Films of Paul Schrader. Fecha de consulta: 3 de febrero de 2020.

https://creativescreenwriting.com/transformation-in-art-the-films-of-paulschrader/

Klinenberg, E. 2013. Going Solo: The extraordinary Rise and Surprising Appeal of Living Alone. New York: Penguin Press.

López-Yepes, J. 2019. "El desarrollo de habilidades informativas y de creación de nuevo conocimiento". Ibersid 13 (1): 29-36.

Putnam, R. 1995. "Bowling Alone: America's Declining Social Capital". Journal of Democracy 6 (1).

Riesman, D. 1981. La muchedumbre solitaria. Barcelona: Paidós Ibérica.

Scorsese, M., director. 1976. Taxi Driver. Con Robert De Niro, Jodie Foster, Cybill Sheperd y Harvey Keitel; Paul Schrader, guion; J. Philips y M. Philips, productores. EE.UU.: Bill/Phillips Productions.

Sennett, R. 2002. El declive del hombre público. Barcelona: Ediciones Península.

Schrader, P. 2018. Transcendental Style in Film. Oakland: Univesity of California Press.

Stanislavski, C. 1975. La construcción del personaje. Barcelona: Alianza Editorial Cine y Comunicación. 
Taubin, A. 2012. Taxi Driver. London: BFI Classics.

Thompson, R 1976. The screenwriter on his breakout film, Taxi Driver. Fecha de consulta: 02 de julio de 2019.

https://www.filmcomment.com/issue/march-april-1976/

Van Dijk, T. A. 1993. "Principles of Critical Discourse Analysis". Discours E Society 4 (2): 249-283.

Vivas Moreno, A. y A. Martos García. 2010. "Los nuevos contextos sensoriales de lectura”. Primeras noticias. Revista de literatura 250: 17-20.

Wade, C. 2017. Classic film series: Martin Scorsese's Taxi Driver. Reino Unido: Wisdom Twin Books.

Para citar este texto:

Valhondo-Crego, José Luis y Agustín Vivas Moreno. 2021. "Lectura crítica del relato audiovisual como fuente de información en el filme Taxi Driver". Investigación Bibliotecológica: archivonomía, bibliotecología e información 35 (87): 171-186.

http://dx.doi.org/10.22201/iibi.24488321xe.2021.87.58342

\section{Anexo}

\section{Código de Análisis}

1. Información sobre filme

a. Año de producción

b. Equipo creativo

c. Duración

d. División estructural

2. Caracterización de personaje guion/imágenes

a. Deseos y necesidades

b. Rasgos objetivos

c. Estados mentales

i. Inferidos por conducta

ii. Ambiguos

d. Voice Over

i. Relato identitario

ii. Sobre otros personajes

e. Planos Subjetivos (POV)

f. Contraste con otros personajes 